\title{
Exploring the role of Luman/CREB3 in regulating decidualization of mice endometrial stromal cells by comparative transcriptomics
}

\author{
Fan Zhao ${ }^{1,2}$, Huan Liu', Nan Wang ${ }^{3}$, Lijun Yư ${ }^{1}$, Aihua Wang ${ }^{1}$, Yanglei Yi ${ }^{4^{*}}$ (D) and Yaping Jin ${ }^{1 *}$
}

\begin{abstract}
Background: Luman is a member of CREB3 (CAMP responsive element-binding) subfamily of the basic leucinezipper (bZIP) transcription factors. It may play an important regulatory role during the decidualization process since Luman was highly expressed in the decidual cells. However, the exact molecular mechanisms of how Luman regulating decidualization is unknown.

Results: Using an in vitro model, we prove that Luman knockdown significantly affects the decidualization process of mice endometrial stromal cells (ESCS) as the expression of two decidual markers PRL8a2 and PRL3C1 were repressed. We employed massively parallel RNA sequencing (RNA-Seq) to understand the changes in the transcriptional landscape associated with knockdown of Luman in ESCs during in vitro decidualization. We found significant dysregulation of genes related to protein processing in the endoplasmic reticulum (ER). Several genes involved in decidualization including bone morphogenetic proteins (e.g. BMP1, BMP4, BMP8A, BMP2, and BMP8B), growth factor-related genes (e.g. VEGFB, FGF10, and FGFR2), and transcription factors (IF4E, IF4A2, WNT4, WNT9A, ETS1, NOTCH1, IRX1, IDB1, IDB2, and IDB3), show altered expression. We also found that the knockdown of Luman is associated with increased expression of cell cycle-related genes including cycA1, cycB1, cycB2, CDK1, CDK2, and PLPK1, which resulted in an increased proportion of ESCs in the G1 phase. Differentially expressed genes (DEGs) were highly enriched on ECM-receptor interaction signaling, endoplasmic reticulum protein processing, focal adhesion, and PI3K-Akt signaling pathways.
\end{abstract}

Conclusions: Luman knockdown results in widespread gene dysregulation during decidualization of ESCs. Genes involved in protein processing in ER, bone morphogenetic protein, growth factor, and cell cycle progression were identified as particularly important for explaining the decidual deficiency observed in this in vitro model. Therefore, this study provides clues as to the underlying mechanisms that may expand our understanding of gene regulation during decidualization.

Keywords: Luman, RNA-Seq, Transcriptomics, Decidualization, Endometrial stromal cell

\footnotetext{
*Correspondence: yyi@nwafu.edu.cn; yapingjin@163.com

${ }^{4}$ College of Food Science and Engineering, Northwest A\&F University,

Yangling 712100, Shaanxi, China

'College of Veterinary Medicine, Northwest A\&F University, Yangling 712100,

Shaanxi, China

Full list of author information is available at the end of the article
}

(c) The Author(s). 2020 Open Access This article is distributed under the terms of the Creative Commons Attribution 4.0 International License (http://creativecommons.org/licenses/by/4.0/), which permits unrestricted use, distribution, and reproduction in any medium, provided you give appropriate credit to the original author(s) and the source, provide a link to the Creative Commons license, and indicate if changes were made. The Creative Commons Public Domain Dedication waiver (http://creativecommons.org/publicdomain/zero/1.0/) applies to the data made available in this article, unless otherwise stated. 


\section{Background}

During mammalian reproduction, the uterus undergoes complex processes including implantation, decidualization, and placentation to maintain pregnancy [1]. After the attachment of embryo(s) to the uterine epithelium, the embryo(s) will breach the luminal epithelial barrier and invade into the underlying uterine stroma, which triggers extensive remodeling of the endometrial stromal compartment [2]. This process is known as decidualization, characterized by the differentiation of stromal fibroblasts into specialized decidual cells that coordinate trophoblast invasion and placenta formation [3]. Decidualization plays a critical role in regulating trophoblast invasion, modulating the local immune response at the feto-maternal interface, and supporting the development of the placenta.

Decidualization is driven by the fluctuation of two ovarian steroid hormones, estrogen (E2) and progesterone (P4) [4]. The cellular actions of these hormones are mediated through intracellular estrogen receptor (ER) and progesterone receptor (PR) proteins, which are hormoneinducible transcription factors [5]. Accumulating evidence has demonstrated that endometrial decidualization is associated with a large-scale rewiring of the gene regulatory network, and transcription factors are of great importance in the transcriptional reprogramming during decidualization. The ER $\alpha$ knockout and PR knockout mouse displayed a failure of decidual response to an artificial stimulus, as well as reproductive abnormalities due to defects in multiple reproductive tissues including embryo implantation and uterine decidualization $[6,7]$. There are some E2 and P4 regulated transcription factors that control the activation and repression of other gene targets during decidualization. For instance, Hoxa10, a member of the homeobox or Hox multigene family of transcription factors, is required for successful implantation as a partial mediator of $\mathrm{P} 4$ signaling [8]. CCAAT/enhancer-binding protein $\beta(\mathrm{C} / \mathrm{EBP} \beta)$, as a member of the basic leucine zipper (bZIP) family of transcription factors, is able to regulate diverse processes of decidualization. Various studies have shown that $\mathrm{C} / \mathrm{EBP} \beta$ is a key mediator of stromal cell proliferation and decidualization by regulating the expression of multiple cell cycle regulatory proteins $[9,10]$.

Luman is a member of CREB3 (cAMP-responsive element-binding) subfamily of the basic leucine-zipper (bZIP) transcription factors. Luman was reported to interact with transcriptional coactivator HCF1 [11], hepatitis $C$ virus core protein [12], and dendritic cellspecific transmembrane protein [13]. It involves diverse reproduction-related processes by regulating cell proliferation, differentiation, and apoptosis. In mouse granulosa cells, knockdown of Luman significantly decreases the concentration of E2 and P4 and promote cell proliferation. It was shown that Luman-deficient mice exhibit low corticosterone, low body weight and decreased pup survival [14]. Previous work in our lab revealed that Luman protein was expressed in the luminal, glandular epithelium, and decidual cells during mouse embryo implantation. Moreover, high expression of Luman was detected in the decidualized cells on day 6 to 8 of pregnancy [15], which pinpoint a potential regulatory role of Luman in decidualization.

In this study, we exploited the RNA-seq approach to investigate the role of Luman during mice stromal cell decidualization. Due to the highly dynamic nature of the transcriptome, we monitored the transcriptional changes at 0,48 , and $72 \mathrm{~h}$ after in vitro decidualization induction. Additionally, we confirmed our RNA-seq gene expression data by quantitative real-time PCR (qRT-PCR). Finally, the promoter region of the genes belong to a putative Luman regulon was analyzed.

\section{Results}

Luman expression in ESCs during in vitro decidualization Our previous study has shown that Luman protein was expressed in decidual cells of the mouse uterus on Day 6 of pregnancy. The expression level was increased when the second decidual zone was formed, while decreased on Day 8 of pregnancy as apoptosis of the decidualized cells occurred [15]. We further evaluate the Luman expression in ESCs using an in vitro decidualization model. The mRNA expression of two important decidualization markers (prl8a2 and prl3c1) was highly upregulated overtime after the decidual stimulus was added, which implies that the in vitro decidualization model was successfully established (Fig. 1a\&b). After 48 and $72 \mathrm{~h}$ of decidualization induction, the Luman expression was significantly upregulated at both mRNA and protein level (Fig. 1c\&d).

\section{Luman knockdown decreases the expression of decidualization markers}

To determine the role of Luman in ESCs, we transfected the cells with Lentivirus carrying Luman shRNA (shLuman) to block the Luman transcription. The transfected cells showed a strong GFP signal under fluorescent microscopy at $48 \mathrm{~h}$ after transfection, indicating a high transfection efficiency of lentivirus (Fig. 2a). After being transfection with shLuman lentivirus, the ESCs showed dramatically decreased mRNA and protein expression of Luman (Fig. 2b \& c). We further used this knockdown system to knockdown Luman during in vitro decidualization of ESCs. Cells sampled at 0, 24, 48, and $72 \mathrm{~h}$ post decidualization induction were used to analyze the expression of Luman and decidualization markers (Fig. 2d). The results showed that the Luman expression was severely reduced at all sampling point (Fig. 2e). The expression of prl8a2 and prl3c1 were significantly downregulated by Luman lentivirus transfection at 48 and $72 \mathrm{~h}$ of in vitro decidualization (Fig. 2f \& g), indicating an impaired decidualization. 

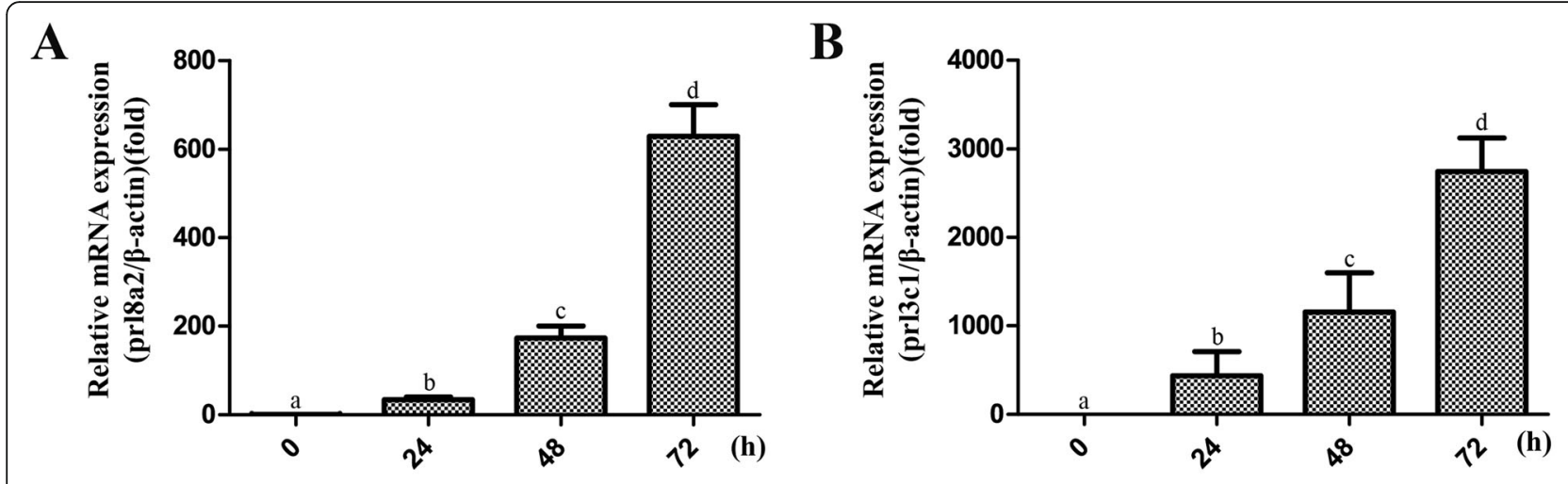

C

D
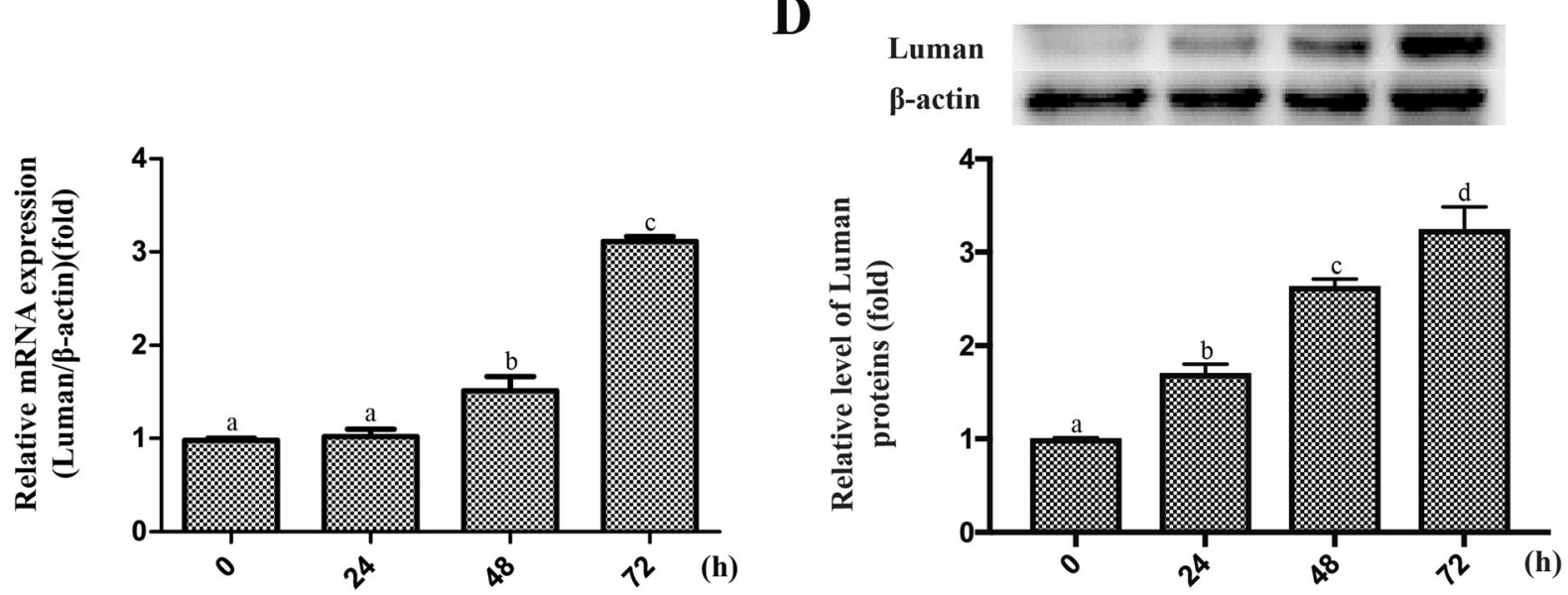

Fig. 1 The expression of decidual marker gene and Luman in ESCs during in vitro decidualization. a \& $\mathbf{b}$ The mRNA expression of prl8a2 and prl3c1 in ESCS at 0, 24, 48, and $72 \mathrm{~h}$ of decidualization. $\mathbf{c} \& \mathbf{d}$ The mRNA and protein expression of Luman in ESCs at $0,24,48$, and $72 \mathrm{~h}$ of decidualization. $P<0.05$ was considered significant. All data are represented as the mean \pm SEM of repeated experiments $(n=3)$

Luman knockdown leads to distinct Transcriptomic landscapes during in vitro decidualization of ESCs

To study the impact of Luman knockdown on the global transcriptome of ESCs during decidualization, we performed RNA-seq $(\approx 50$ million reads per sample) of shLuman- or shNC- lentivirus transfected cells collected at 0,48 , and $72 \mathrm{~h}$ after decidualization induction. This is based on our in vitro model that the decidualization was significantly affected by Luman knockdown at 48 and $72 \mathrm{~h}$ (Fig. 2f\&g). Four technical replicates (individual wells) were pooled into one biological replicate. Two biological replicates were used for each time point. For RNA-seq data analyzing, raw reads were trimmed and aligned to the genome of Mus musculus. Reads were then counted and classified. After trimming, more than $95 \%$ of the raw reads with good quality (clean reads) were used further analysis. In the mapping step, about $90 \%$ clean reads were mapped to exons of the mouse genome, and about $10 \%$ clean reads were mapped to introns or intergenic region (Fig. 3a). To compare gene expression, we normalized expression values using DESeq R package (1.18.0) and centered the values. The centered normalized values were visualized as a heat map, which showed obvious clusters of co-expressed genes and clear gene expression differences between Luman knockdown and control group (Fig. 3b). Of the three Luman knockdown groups, ESCs sampled at $0 \mathrm{~h}$ of decidualization have least number of differentially expressed genes (188 DEGs), and ESCs sampled at 48 and $72 \mathrm{~h}$ of decidualization have 6320 and 1569 DEGs, respectively (Fig. 3c). An additional file shows DEGs in more detail [see Additional file 3].

\section{Validation of RNA-seq by RT-qPCR}

To validate the dual RNA-seq data by RT-qPCR, we chose several genes from three sample time point: seven genes from $0 \mathrm{~h}$ (JUND, RS18, PRC2A, AIF1L, CNN2, RN181), eight genes from 48 h (IOD3, ZBT16, LR14B, ATPD, CEBPA, MK67I, LG3BP, BOK), and five genes from $72 \mathrm{~h}$ (MMP12, LYZ2, PHYIP, TCTP, PPR3B). The target genes were selected because of their varied expression profiles: increasing, decreasing, or unchanged. The cycle thresholds $(\mathrm{Ct})$ for ESCs transcripts were normalized against $\beta$-actin. The reference genes were highly expressed and did not show significant changes between 

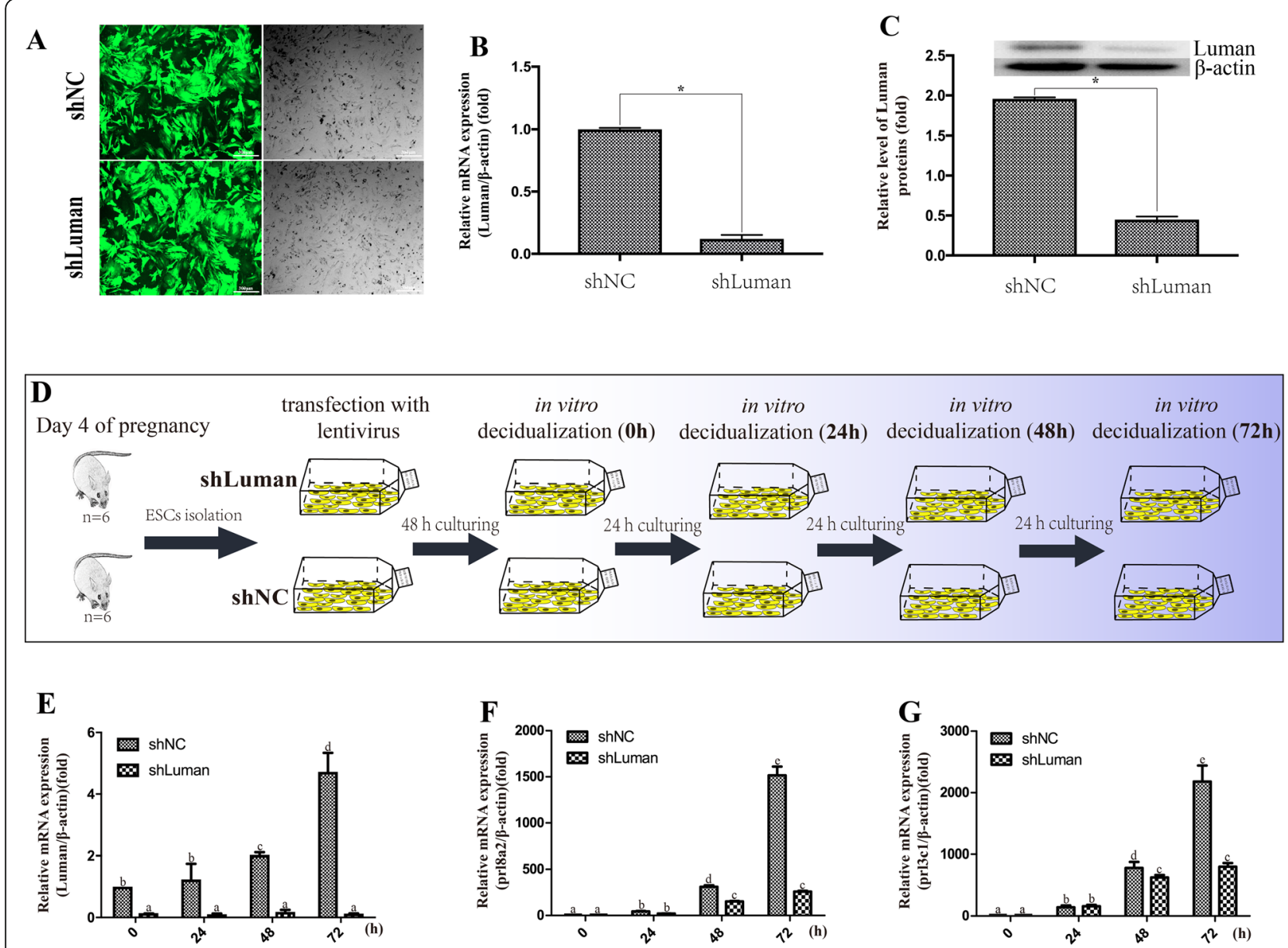

Fig. 2 Transfection and knockdown efficiency of shLuman on ESCs and the effects of Luman knockdown on decidualization of ESCS. a Transfection efficiency was observed by fluorescence microscopy in the shNC and shLuman transfected ESCs. b \& c The Luman mRNA and protein expression level were detected in the shNC and shLuman groups. $\mathbf{d}$ The setup with Luman being silenced during different time point after decidualization induction. e-g mRNA expression of Luman, prl8a2, and prl3c1 in ESCs at 0, 24, 48, and $72 \mathrm{~h}$ of decidualization. $P<0.05$ was considered significant. All data are represented as the mean \pm SEM of repeated experiments $(n=3)$

any time points during decidualization. The RT-qPCR fold change was calculated by the $2^{-\Delta \Delta \mathrm{Ct}}$ method. Fold changes obtained by RT-qPCR and RNA-seq showed a relatively high correlation with $\mathrm{R}^{2}$ of 0.7001 (Fig. 4), validating the reliability of the RNA-seq data.

\section{Luman regulates the ER-associated protein processing during in vitro decidualization of ESCs}

As Luman belongs to the bZIP family whose inactive precursor is localized in the ER membrane, we first examined the genes involved in ER-associated protein processing pathway (Fig. 5). Our results showed that ERassociated genes were prominently affected in Lumanknockdown cells, especially after $48 \mathrm{~h}$ of decidualization. The expression of the main ER stress indicator GRP 78 (Bip), as well as its Nucleotide Exchange Factors (NEF, Grp170, and Sil1) [16], are upregulated in of $48 \mathrm{~h}$ decidualized ESCs. Another important ER stress chaperone,
GRP 94, was also upregulated, indicating an elevated level of unfolded protein in the ER lumen. Endoplasmic reticulum protein folding related genes such as GlcII, CNX, ERP57, and the expression of SAR1 and Sec23/24, which are related to the transport of proteins from the endoplasmic reticulum to the Golgi apparatus, are also upregulated. When the unfolded protein accumulated, part of them enters the ubiquitin-proteasome pathway and eventually being degraded by cytosolic proteasomes. As shown in Fig. 5, the expression of genes involved in the ubiquitin-proteasome pathway including PDIs, TRAP, OS9, and Bap31, etc. were upregulated. In the meantime, the accumulation of misfolded/unfolded proteins within the endoplasmic reticulum (ER) lumen will trigger a signaling pathway named unfolded protein response (UPR) [17]. The UPR signaling activation is also observed in our dataset, as the expression of several genes in the PERK signaling pathway were upregulated. 


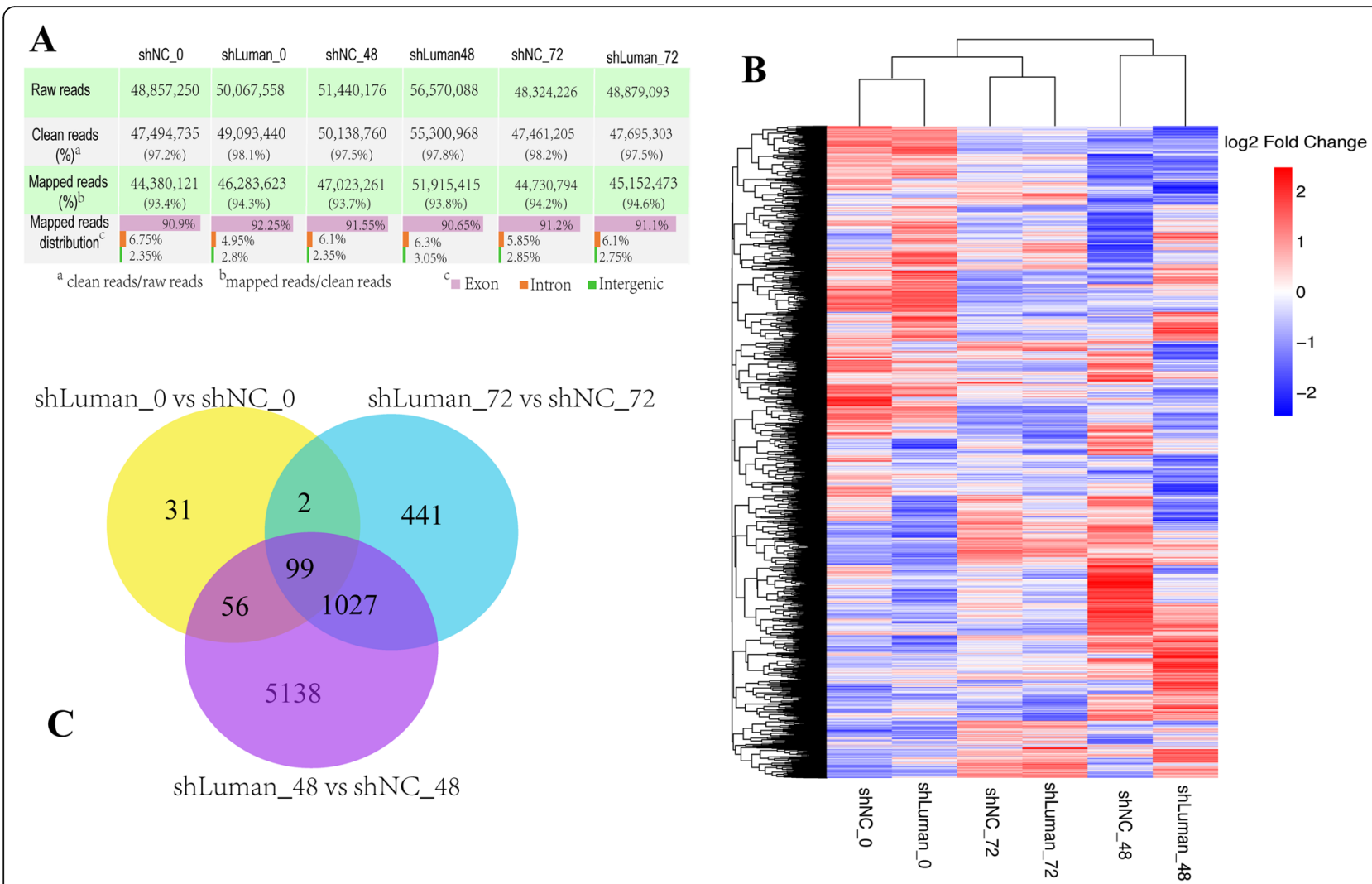

Fig. 3 RNA-seq data analysis of in vitro decidualized ESCs in shLuman (Luman knockdown) and shNC (control) group. a On average, there are about 50 million reads per library: above $93 \%$ of the clean reads aligned to the mouse genome, with about 91\% mapped reads located in Exons. b Gene expression in different libraries was normalized, centered, and clustered. Blue indicates relatively lower expression while red indicates a higher value. c Venn diagram showing the number of genes with altered expression at 0,48 , and $72 \mathrm{~h}$

\section{Luman regulates the expression of decidualization-related genes}

To further investigate the effects of Luman knockdown on the decidualization of ESCs, we analyzed several groups of genes that directly related to the decidualization process. In bone morphogenetic proteins (BMP), the expression of BMP1, BMP4, BMP8A, and BMP8B was significantly upregulated at 48 and $72 \mathrm{~h}$ of decidualization, while the expression of BMP2 was significantly downregulated at both time points (Fig. 6a). Among the growth factor-related genes, the majority of these genes are down-regulated at 48 and $72 \mathrm{~h}$ of decidualization, with VEGFB and FGF10 showed upregulation at both sampling points. FGFR2 was significantly upregulated at $48 \mathrm{~h}$ and significantly down-regulated at $72 \mathrm{~h}$ of decidualization (Fig. 6b). The expression profile of transcription factors associated with decidualization is relatively complex. Among them, the expression of IF4E, IF4E2, IF4E3, IF4A2, WNT4, WNT9A, ADM, ETS1, NOTCH1, IRX1 gene showed down-regulation at $48 \mathrm{~h}$ and $72 \mathrm{~h}$ of decidualization, while the expressions of IDB1, IDB2 and IDB3 were up-regulated at both time points (Fig. 6c). In addition, there are some other decidual-related genes showed significantly altered expression after Luman knockdown. For example, the expression of NOS2 is significantly downregulated by Luman at two time points. ANGP2 was significantly down-regulated at $48 \mathrm{~h}$ and significantly upregulated at $72 \mathrm{~h}$ of decidualization. The trend of PRLR is opposite to that of ANGP2, from a significant upregulation to a significant downregulation (Fig. 6d).

\section{Effects of Luman knockdown on cell cycle of ESCs during in vitro decidualization}

The cell cycle of decidual ESCs was measured by flow cytometry, and the expression of several important cyclins and their corresponding cyclin-activating enzymes were analyzed. After Luman knockdown, the proportion of ESCs in the G1 phase has increased at both 48 and $72 \mathrm{~h}$ of decidualization (Fig. 7a). The RNA-seq data revealed a dramatic expression change of cell cyclerelated genes. Cyclin A2 (cycA2), cyclin B1 (cycB1), and cyclin B2 (cycB2) were significantly upregulated at 48 and $72 \mathrm{~h}$ of decidualization, while cyclin D1 (cycD1) was significantly downregulated at both time points. The expression of cyclin kinase 1 (CDK1), cyclin kinase 2 


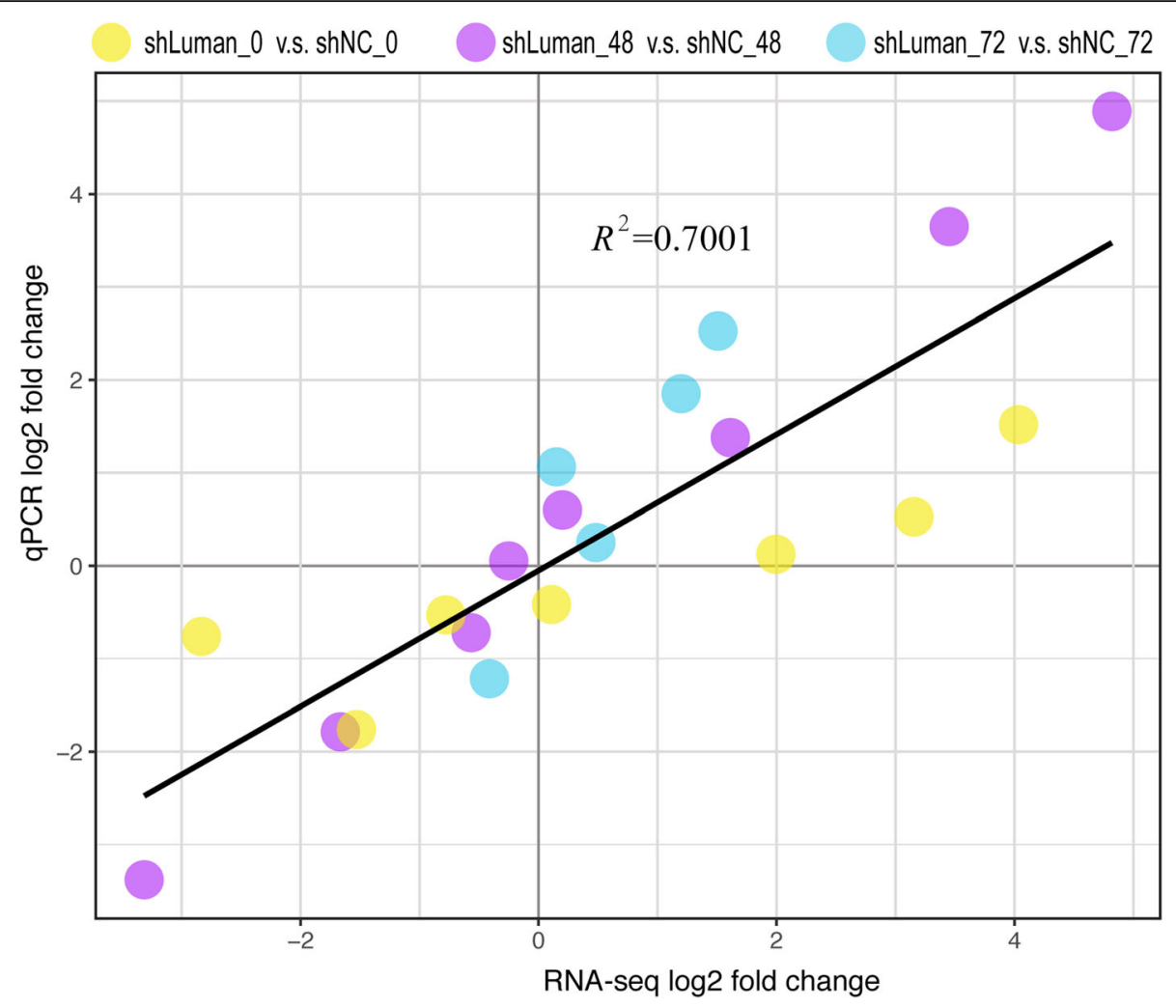

Fig. 4 Validation of RNA-seq by RT-qPCR. The study was repeated in duplicates and total RNA was isolated as previously described. Several genes were chosen as validation targets. The fold changes from RT-qPCR against dual RNA-seq foldchanges were plotted with a high degree of correlation

(CDK2), and Polo-like kinase 1 (PLK1) was also significantly upregulated at both time points (Fig. 7b).

\section{Functional validation of representative DEGs}

Representative DEGs correlated with ER stress, BMP, growth factor, and cell cycle were selected for functional validation with real-time quantitative PCR assay. Gene expression pattern detected with RT-qPCR was consistent with RNA-seq (Fig. 8). RT-qPCR assay showed that the expression of CHOP was upregulated at 48 and $72 \mathrm{~h}$. The expression level at $72 \mathrm{~h}$ was slightly conflicting with the RNA-seq. This can be explained by the fact that most ER stress-related genes were mostly upregualated and CHOP is a well-documented ER stress marker.

\section{Analysis of the signal pathway of differentially expressed genes (DEGs)}

All DEGs were subjected to functional analysis using the KEGG (Kyoto Encyclopedia of Genes and Genomes) database and were categorized according to the pathways involved. An additional file shows this in more detail [see Additional file 4]. The 20 signal pathways with the most enriched genes are shown in Fig. 9. The results showed that the gene enrichment was highest on the ECM-receptor interaction signaling pathway, with 56 and 26 genes (88 genes in the database) being significantly altered at 48 and $72 \mathrm{~h}$ of decidualization, respectively. In the $48 \mathrm{~h}$ decidual group, the endoplasmic reticulum protein processing was the second most significant pathway. In addition, the focal adhesion and endocytosis pathways also showed significant changes in genes (Fig. 9a). Similar to the $48 \mathrm{~h}$ decidual group, the focal adhesion-related genes were also highly enriched in the $72 \mathrm{~h}$ decidual group. Moreover, 57 genes were significantly altered in the phosphatidylinositol 3-kinase/ Protein Kinase B (PI3K-Akt) signaling pathway, of which 30 genes were up-regulated and 27 genes were downregulated (Fig. 9b).

\section{Analysis of Luman regulated genes}

To investigate the genes that directly regulated by Luman, we selected genes that were consistently expressed in RNA-seq data: both up- or down-regulated at three sampling point $(0,48$, and $72 \mathrm{~h}$ of decidualization). After the addition of the Luman stimulant BFA, the expression of these genes was again determined by RT-qPCR. If the trend at three time points was opposite to the RNA-seq data, the gene is likely to be directly regulated by Luman. As shown in Fig. 10a, the five genes STMN4, CNN2, MLP3B, TRPA1, and NPTX2 were significantly down- 


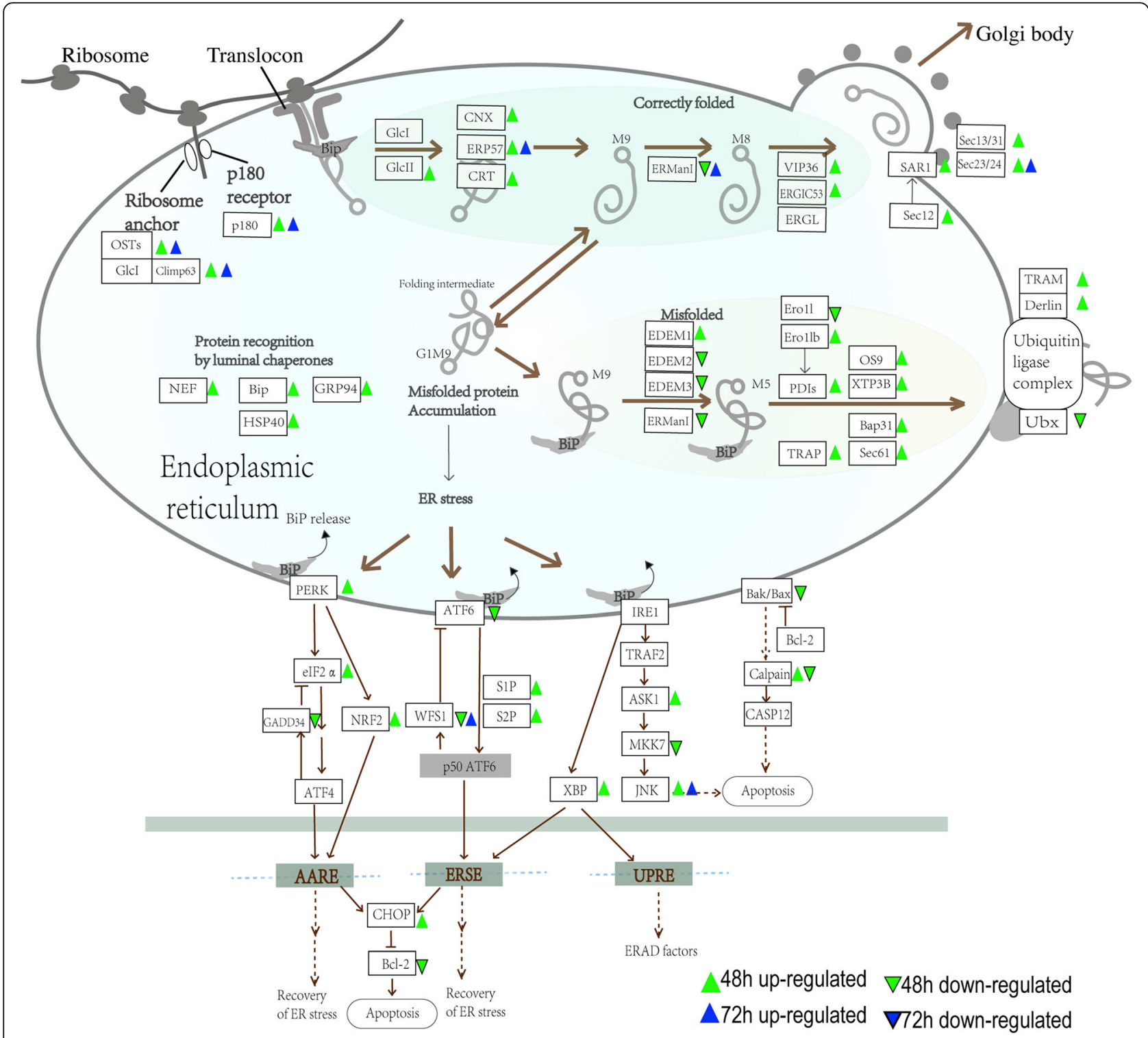

Fig. 5 Protein processing pathway in endoplasmic reticulum was affected by Luman knockdown during decidualization. A regular triangle indicates upregulated genes and the inverted triangle indicates downregulated genes

regulated at all time points after Luman knockdown, while the two genes TRFL and IOD3 were significantly upregulated at three time points. After treatment of ESCs with BFA, Luman expression was significantly upregulated. At the same time, the expression of STMN4, CNN2, MLP3B, TRPA1, NPTX2 was upregulated, while the expression of TRFL and IOD3 was significantly downregulated. Previous studies have demonstrated that Luman regulates the expression of downstream genes by binding to specific sites in the promoter region. Known Luman regulatory sites include CREB3 and C/EBP conserved sequences [18], the sequences of which are shown in Fig. 10b and the letter size indicates the probability of occurrence of a particular base at that site. By analyzing the promoter sequences of the above seven genes, it was found that the C/EBP binding sequence was detected in the promoter regions of all genes, and the direct binding sequence of Luman was detected in the promoter regions of NPTX2, MLP3B, and CNN2 genes. These genes may be directly regulated by Luman and play an important role in the decidualization process (Fig. 10c).

\section{Discussion}

This study applied RNA-seq to investigate the effects of Luman knockdown on the gene expression of decidualized ESCs based on an in vitro decidualization model. 

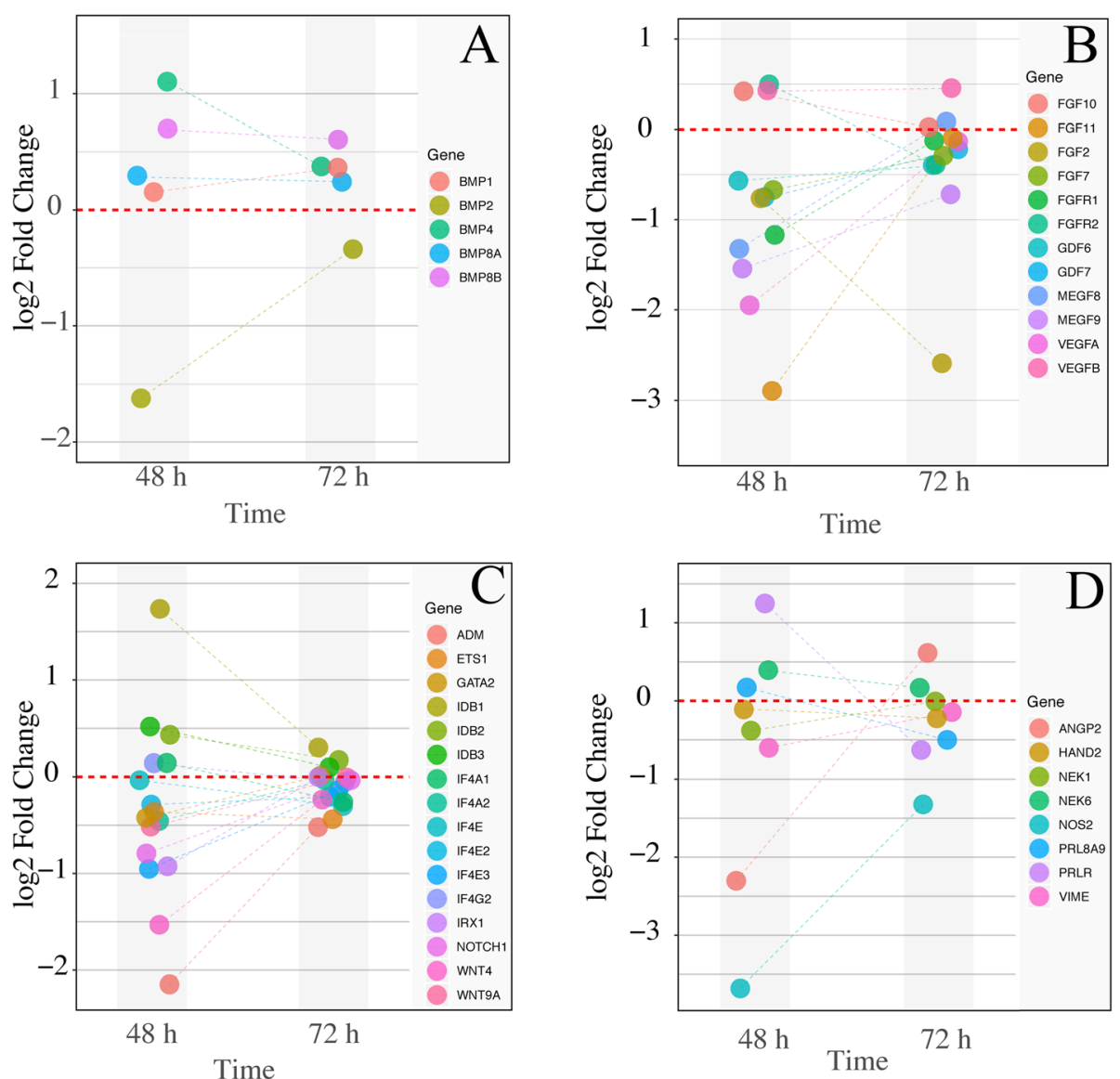

Fig. 6 The functionality of decidualization was altered by Luman knockdown. Several genes known to be involved in decidualization were picked and their expression pattern at 48 and $72 \mathrm{~h}$ are shown. a Genes annotated as bone morphogenetic protein (BMP). b Genes annotated as growth factors. c Genes annotated as transcription factors. d Other genes

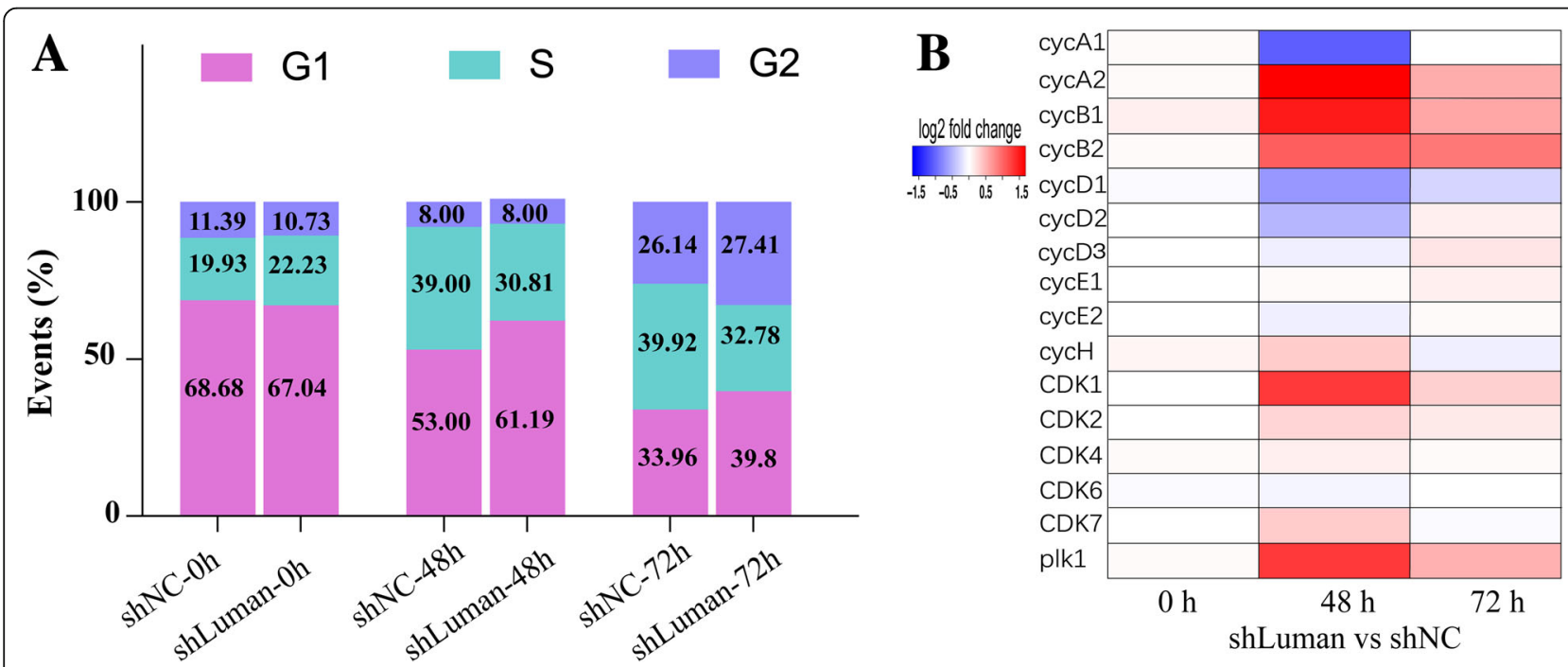

Fig. 7 Effects of Luman knockdown on cell cycle of ESCs during decidualization. a Analysis of ESCs' cell cycle by FACS after in vitro decidualization for 48 and $72 \mathrm{~h}$. b Expression of cell cycle-associated genes in decidual cells at 48 and $72 \mathrm{~h}$ 

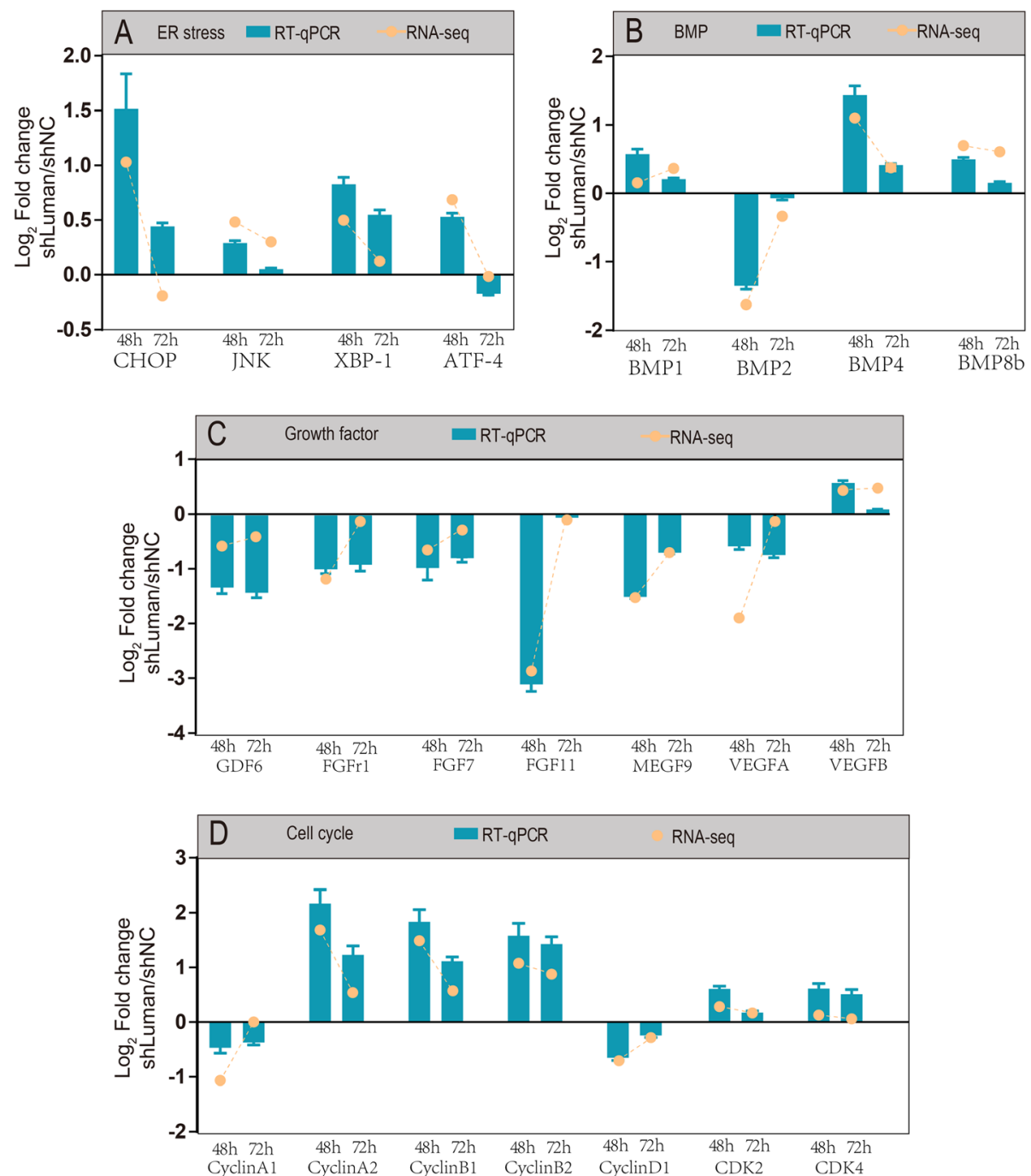

Fig. 8 Functional validation of representative DEGs involved in (a) ER stress, b BMP, c Growth factor, and $\mathbf{d}$ Cell cycle pathways. The histogram shows the RT-qPCR results and the dot indicates the RNA-Seq results

In this model, the effect of Luman knockdown on two decidual markers prl8a2 and prl3c1 began to appear after $48 \mathrm{~h}$ of decidualization induction, and the effect was more significantly inhibited after $72 \mathrm{~h}$ of induction. Therefore, cells at these two points were collected for RNA-seq analysis. The results show that the gene expression of the decidualized 0 -h cells was not significantly affected by Luman, but was significantly affected by Luman at 48 and $72 \mathrm{~h}$ of decidualization.

As a transcription factor localized in the endoplasmic reticulum membrane and a potential ER stress sensor, Luman knockdown significantly increases the level of unfolded protein and therefore affects the expression of ER protein processing-related genes. Sequentially, the expression of key genes of ER-associated protein degradation (ERAD) pathway was significantly upregulated. Termine et al. reported that the transcriptional elevation of EDEM1 boosts the efficiency of ERAD through the formation of a complex that suppresses the proteolytic downregulation of ER mannosidase I (ERManI) [19], which was also verified in this study. OS-9 and XTP3B are capable of binding to misfolded proteins and link ERAD substrates to the membrane-associated ubiquitination machinery [20]. In this study, the expression levels of OS-9 and XTP3B were significantly up-regulated, indicating that Luman knockdown increases the activity of ERAD and related ubiquitination degradation pathway. Moreover, the ER stress receptor IRE1 and its downstream genes were up-regulated, suggesting that Luman knockdown causes unfolded protein responses reaction in cells.

Luman knockdown affects the expression of a wide range of genes related to decidualization. The expression of several bone morphogenetic proteins (BMP) was altered. Among them, BMP2 was significantly 


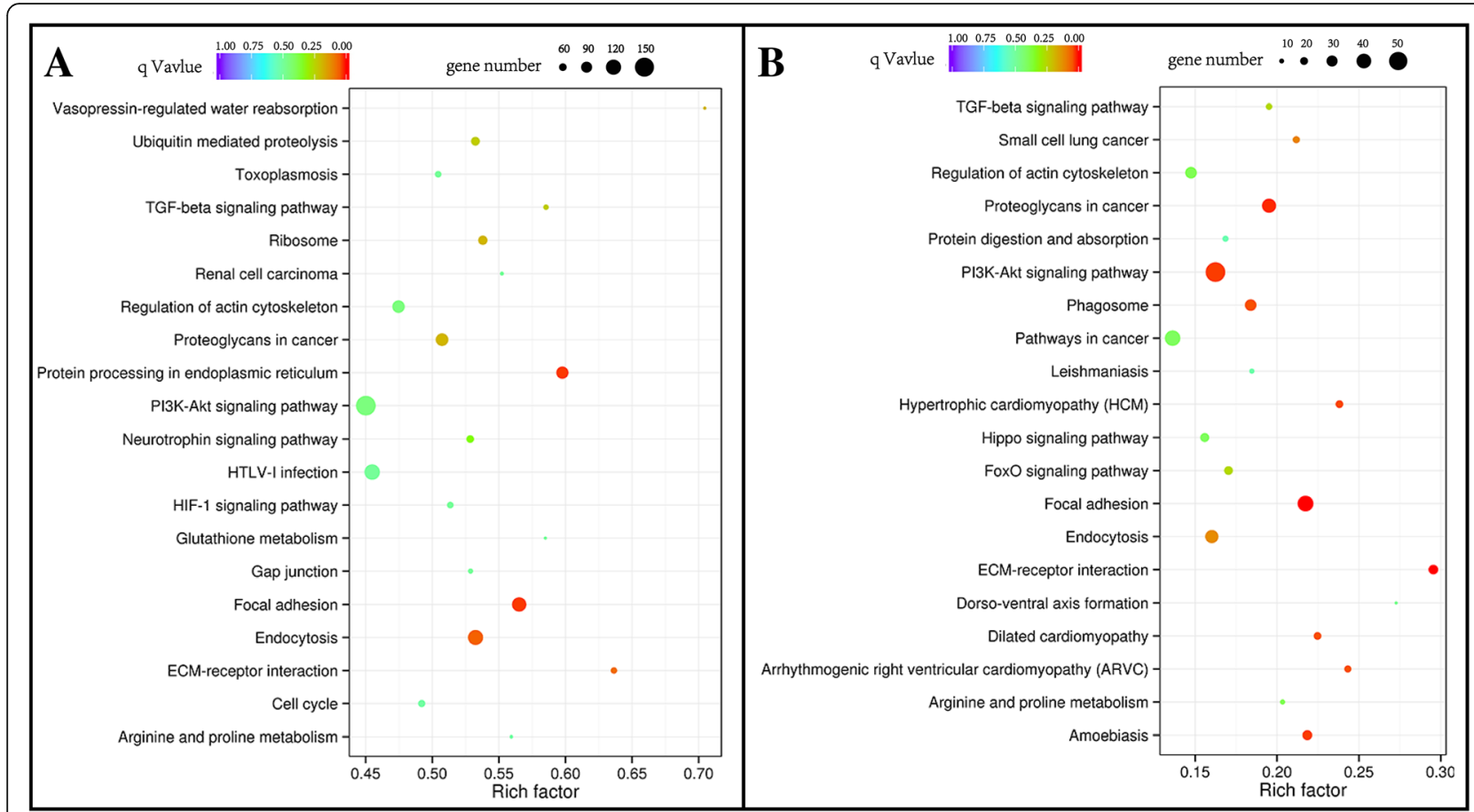

Fig. 9 Gene set enrichment analysis and pathway analysis of differentially expressed genes after Luman knockdown in ESCs at (a) $48 \mathrm{~h}$ and (b) $72 \mathrm{~h}$ of decidualization

downregulated, while BMP1, BMP4, and BMP8 were significantly upregulated at $48 \mathrm{~h}$ and $72 \mathrm{~h}$ of decidualization. BMP2 has been reported as a key regulator of gene expression and function in mouse uterine decidualization [21]. The role of BMP1, BMP4, and BMP8 in decidualization has not been reported, and the specific mechanism needs further study. The expression of many growth factor-related genes was down-regulated in both 48 and $72 \mathrm{~h}$ decidualized ESCs. These genes play important roles in decidualization or cell growth and differentiation. For instance, FGF7 and FGFR2 can stimulate the proliferation of human ESCs and the expression of insulin-like growth factor-binding protein 1 and prolactin in an autocrine manner through the PERK and JNK signaling pathways [22]. FGF-10 and FGFR-1 have key roles in decidual-trophoblast interaction [23]. GDF7 is important for interneurons and sensory neurons, as well as for the development of seminal vesicles [24]. Luman's knockdown led to a significant down-regulation of WNT4, which is a critical regulator not only of proper postnatal uterine development but also embryo implantation and decidualization [25]. Moreover, downregulation of Nothc1 and NOS2 may have a direct effect on decidualization. The Notch1 signaling is involved in inhibiting apoptosis of stromal fibroblasts and regulate cell cycle progression prior to embryo implantation, thereby ensuring the success of decidualization [26]. $\mathrm{NOS}_{2}$ plays an important role in maintaining the integrity of the decidual cells and the normal development of the uterine vascular system and may have the effect of promoting the survival of the embryo [27].

The signal pathway enrichment analysis showed that the extracellular matrix-receptor interaction (ECM-receptor interaction) signaling pathway enriched most DEGs after Luman knockdown. The decidual stromal matrix undergoes extensive reorganization beginning at the periimplantation period since the extracellular matrix (ECM) provides mechanical support for the epithelium, stroma, and vessels during decidualization [28]. The transcriptomic study on decidualization of rat stromal cells revealed that the ECM-related genes were significantly up-regulated [29]. During the decidualization process, the structure and molecular composition of the endometrial extracellular matrix (ECM) undergone significant changes [30]. The focal adhesion signaling pathway is also significantly enriched. It is reported that the focal adhesion kinase on decidual cells is important in development and differentiation following attachment [31]. In rats, focal adhesion-associated proteins are involved in the invasion of the blastocyst into the endometrial decidual cells [32]. In the $72 \mathrm{~h}$ decidual group, DEGs were significantly enriched in the PI3K/Akt signaling pathway. Fabi and coworkers found that Akt expression is down-regulated in human ESCs, and the inhibition of the PI3K pathway may be involved in decreased cell motility 


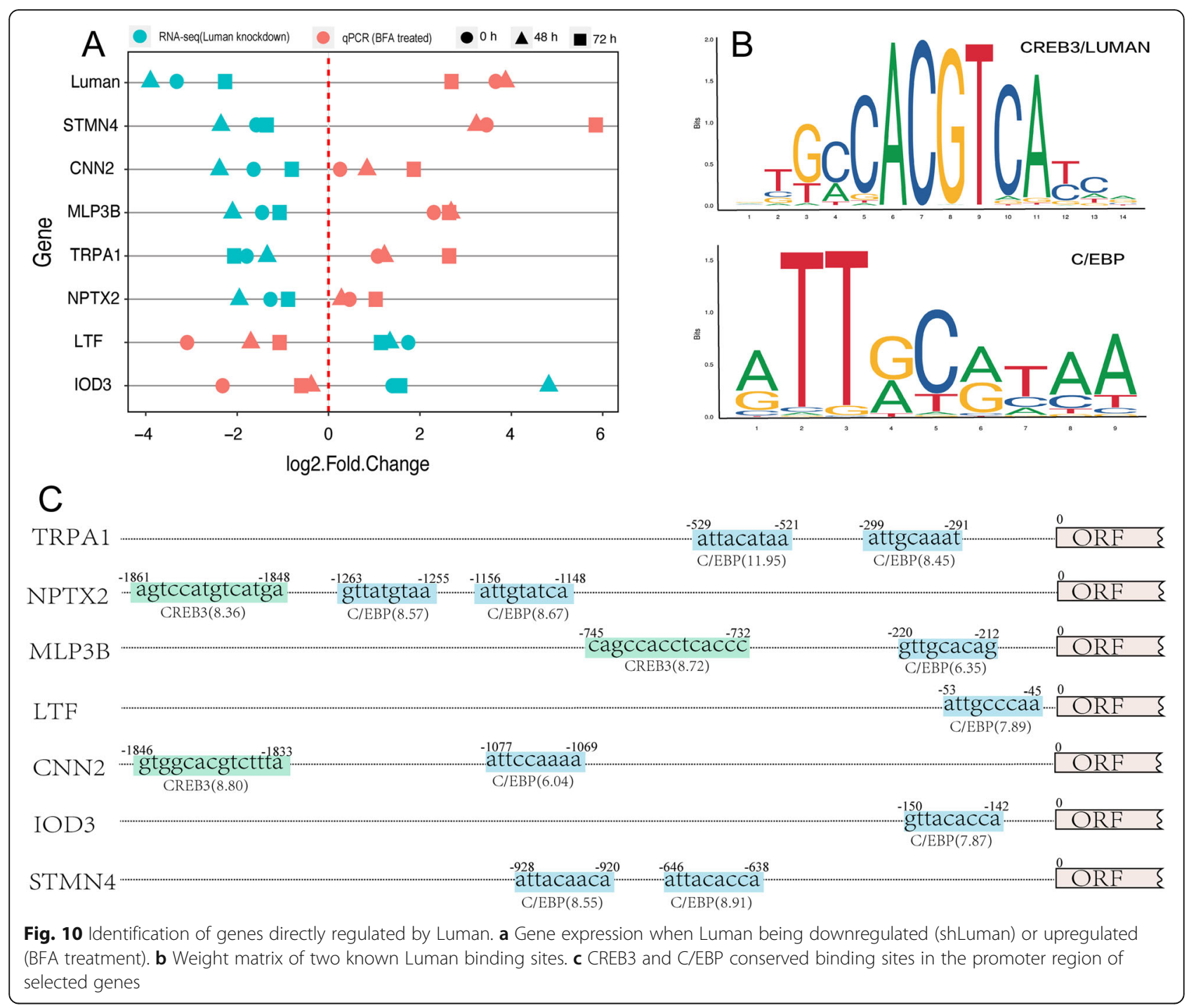

during decidualization [33]. Similarly, knockdown of nonmetastasis gene 23 (nm23) in ESCs of mouse and human decreased cell proliferation and decidualization through the PI3K/Akt signaling pathway [34].

A group of genes shows consistent expression patterns in the 0,48 , and $72 \mathrm{~h}$ decidual groups after Luman knockdown. We speculate that those genes are directly regulated by Luman. Furthermore, when ESCs were treated by BFA (to elevate Luman expression), high consistency in mRNA expression of STMN4, CNN2, MLP3B, TRPA1, NPTX2, TRFL and IOD3 was observed again. Lu et al. reported that Luman control gene transcription by binding to certain conserved sites in the promoter region of the downstream genes. These sites include CREB (Luman) or C/EBP conserved sequence [18]. Of the genes with similar expression pattern, we found at least one Luman-binding site in their promoter region, which further prove those genes are potentially belong to Luman regulon.

\section{Conclusions}

In summary, Luman plays an important role in the decidualization of ESCs. Knockdown of Luman causes an increase in unfolded proteins in the endoplasmic reticulum, affecting stromal cell cycle and the expression of decidual-related genes. These regulatory effects are associated with the endoplasmic reticulum signaling pathway, the extracellular matrix, and the PI3K/Akt signaling pathway.

\section{Methods}

\section{Animal}

Female adult Kunming White mice (SPF grade, 7-9 weeks old) were purchased from Experimental Animal Center of The Fourth Military Medical University. All the mice were caged in a controlled environment with a cycle of $12 \mathrm{~L}$ : $12 \mathrm{D}$ at $22^{\circ} \mathrm{C}$. All procedures were approved by the Committee for the Ethics on Animal Care and Experiments in Northwest A\&F University. 


\section{ESCs isolation and in vitro decidualization induction}

To set up the matings, female mice in estrus are placed into the cages with males (two females in each cage with one male). In the next morning, females were checked for vaginal plugs for successful mating. A total of twelve female mice were used for the study (shLuman, $n=6$; shNC, $n=6$ ). To minimize suffering during sacrifice, mice on day 4 of pregnancy were euthanized by cervical dislocation. ESCs were isolated from fresh endometrial tissue and were cultured at $37^{\circ} \mathrm{C}$ with $5 \% \mathrm{CO}_{2}$. The epithelial and stromal cells were separated by the adhesion purification method (see Additional file 1). In vitro decidualization induction was performed as previously described [35]. Briefly, the confluence ESCs from the third passage after thaw were treated with $10 \mathrm{nM}$ of estradiol-17b (E2; Sigma-Aldrich, Germany) and $1 \mu \mathrm{M}$ of progesterone (P4; Sigma-Aldrich, Germany) to induce decidualization. Culture medium was changed every 2 days. Cells were observed and photographed with an inverted microscope during the treatment period (see Additional file 2).

\section{Transfection of ESCs with shLuman lentivirus}

Lentivirus vectors bearing the Luman shRNA sequence (shLuman) and the non-silencing sequence (shNC) were constructed previously [36]. shLuman lentivirus was packaged as described by Chen et al [37]. The supernatant of cell culture containing shLuman or shNC lentivirus was stored at $-80^{\circ} \mathrm{C}$. One day prior transfection, about $2 \times 10^{5}$ ESCs were seeded into 6-well plate with 50-60\% confluence. The complete culture solution was replaced by $2 \mathrm{ml}$ lentiviral particles with $2 \mu \mathrm{l}$ polybrene $(8 \mathrm{mg} / \mathrm{ml}$; GeneChem Co., Ltd., China). After $12 \mathrm{~h}$, the lentivirus solution was replaced by complete culture medium and cultured for $48 \mathrm{~h}$. Cells were collected for downstream experiments.

\section{RNA isolation, sequencing, and data analysis}

ESCs were transfected by Lentivirus carrying either Luman shRNA sequence (shLuman) or the non-silencing sequence (shNC). Cells were cultured for $48 \mathrm{~h}$ to allow Luman knockdown, decidual stimulus was then added and was designated as $0 \mathrm{~h}$ post decidualization. Samples were taken at 0,48 , and $72 \mathrm{~h}$ post decidualization from shLuman or shNC group. Six technical replicates (individual wells) were pooled into one biological replicate. Two biological replicates were used for each time point. Total RNA was isolated from ESCs with the TRIzol reagent (TaKaRa Bio Inc., Japan), RNA quantity and purity were determined by a NanoDrop spectrophotometer and $1 \%$ agarose gel. The RNA integrity was assessed using the RNA Nano 6000 Assay Kit of the Bioanalyzer 2100 system (Agilent Technologies, CA, USA).

A total amount of $3 \mu \mathrm{g}$ RNA per sample was used as input material for the RNA sample preparations. NEBNext ${ }^{\circ}$
Ultra $^{\mathrm{Tm}}$ RNA Library Prep Kit for Illumina ${ }^{\circledR}$ (NEB, USA) was used to prepare sequencing libraries following the manufacturer's recommendations. Index codes were added to attribute sequences to each sample. cDNA fragments of preferentially $250 \sim 300 \mathrm{bp}$ in length were obtained by purifying the library fragments with AMPure XP system (Beckman Coulter, Beverly, USA). After PCR amplification, the products were purified (AMPure XP system) and library quality was assessed on the Agilent Bioanalyzer 2100 system. The library preparations were sequenced on an Illumina Hiseq platform and $125 \mathrm{bp} / 150 \mathrm{bp}$ paired-end reads were generated.

Raw reads were processed through in-house Perl scripts to remove reads containing adapter, reads containing poly- $\mathrm{N}$, and reads of low quality. At the same time, Q20, Q30 and GC content of the clean data were calculated. All the downstream analyses were based on clean data with high quality. Reference genome and gene model annotation files were downloaded from the NCBI website directly. Index of the reference genome was built using Bowtie v2.2.3 and paired-end clean reads were aligned to the reference genome using TopHat v2.0.12. HTSeq v0.6.1 was used to count the reads numbers mapped to each gene. And then FPKM of each gene was calculated based on the length of the gene and reads count mapped to this gene. Differential expression analysis of two conditions/groups (two biological replicates per condition) was performed using the DESeq $\mathrm{R}$ package (1.18.0). Genes with an adjusted $P$-value $<0.05$ found by DESeq were assigned as differentially expressed. The sequence reads of this study have been submitted to the NCBI Sequence Read Archive (SRA) under accession number SRP216935.

\section{RT-qPCR}

One microgram of total RNA was treated with DNase-I (TaKaRa Bio Inc., Japan) and subjected for cDNA synthesizing using the PrimeScript ${ }^{\mathrm{Tm}} \mathrm{RT}$ reagent Kit (TaKaRa Bio Inc., Japan). RT-qPCR was performed with a LightCycler system (iQ5, Bio-Rad, USA). Each reaction was performed in a total $20 \mu \mathrm{l}$ reaction system containing $10 \mu \mathrm{l} 2 \times \mathrm{SYBR}^{\circ}$ Premix Ex Taq ${ }^{\mathrm{Tm}} \mathrm{II}(\mathrm{Tli}$ RNaseH Plus, TaKaRa Bio Inc., Japan), $2 \mu \mathrm{l}$ cDNA, $0.8 \mu \mathrm{l}$ of each primer $(10 \mu \mathrm{M})$ and $6.4 \mu$ l of nuclease-free water. RT-qPCR primers were designed using PerlPrimer (http://perlprimer.sourceforge. net/) software across intron/exon boundaries. Primer sequences are listed in Additional file 5 and $\beta$-actin gene was included as a housekeeping gene. Moreover, melting curve analysis was performed after real-time PCR reactions to monitor PCR product specificity. At least three biological replicates were performed for each sample. Relative fold change was analyzed according to the $2^{-\Delta \mathrm{Ct}}$ method against housekeeping gene $(\beta$-actin). 


\section{Western blot analysis}

The total protein isolation and protein quantification were performed as previously described [36]. The protein samples were stored at $-80^{\circ} \mathrm{C}$ for subsequent use. For SDS-PAGE, the samples were separated on $12 \%$ polyacrylamide gel and transferred to PVDF membranes (Millipore, Bedford, MA). The membranes were blocked for $1 \mathrm{~h}$ in 10\% skimmed milk diluted in Tris-buffered saline (TBS) and incubation for $1 \mathrm{~h}$ at Room temperature with primary antibodies: anti-Luman (1:400, made by our laboratory, see reference for details [15]) or anti- $\beta$ actin (1:1000, Tianjin Sanjian Biotech Co., Ltd., Tianjin, China). After being washed three times with TBS containing $0.1 \%$ Tween-20, membranes were incubated with corresponding secondary antibody conjugated to HRP (1:2000, Zhongshan Golden Bridge Biotechnology, China) for $1 \mathrm{~h}$ at room temperature. Finally, the bands were visualized utilizing Gel Imaging System (Tannon Science \& Technology Co. Ltd., China) and then analyzed with the Quantity One software (Bio-rad, USA).

\section{Cell cycle analysis}

Cell cycle analysis was performed as previously described [36]. Briefly, transfected ESCs $\left(2 \times 10^{5}\right.$ cells/well in 6-well plate) were washed with PBS and fixed in ice-cold $70 \%$ ethanol overnight at $4{ }^{\circ} \mathrm{C}$. Then, cells were stained with propidium iodide/RNase A solution at $37^{\circ} \mathrm{C}$ for $30 \mathrm{~min}$ in a dark chamber. Flow cytometric analyses were conducted using a BD FACS Calibur system. For each determination, a minimum of 20,000 cells was analyzed. All experiments were repeated three times.

\section{BFA treatment and promoter analysis}

We hypothesized that genes with consistent expression changes at 0,48 , and $72 \mathrm{~h}$ of decidualization possibly have conserved Luman-binding sites in their promoter region. To prove this hypothesis, we treated the cells with brefeldin A (BFA, $1 \mu \mathrm{g} / \mathrm{mL}$ ) for $18 \mathrm{~h}$ to up-regulate the expression of Luman. Cells were decidualized for $0,48,72 \mathrm{~h}$, and then RNA was extracted and subjected to RT-qPCR analysis. Genes with same expression pattern in Luman up-regulated (BFA treatment) or down-regulated (Luman knockdown) group were identified as potential Luman-regulated genes, whose promoter sequence were analyzed for Luman-binding sites by using the JASPAR [38] database.

\section{Supplementary information}

Supplementary information accompanies this paper at https://doi.org/10. 1186/s12864-020-6515-2.

Additional file 1. Morphology of mouse primary endometrial stromal cells (arrows indicate mouse endometrial stromal cells). (A) Non-adherent endometrial stromal cells and other impurity cells that have just been isolated; (B) Endometrial stromal cells and impurities after $2 \mathrm{~h}$ of culture; (C)
After $24 \mathrm{~h}$ of culture, mostly mouse endometrial stromal cells have irregular prismatic or triangle shape.

Additional file 2. In vitro decidualization induction of endometrial stromal cells. (A) Endometrial stromal cells were adhered for $24 \mathrm{~h}$ after isolation and were recorded as in vitro decidualization induction for $0 \mathrm{~h}$. The cell was small with good translucency, and the shape showed irregular rhomboid or triangle. (B) In vitro decidualization induction for $24 \mathrm{~h}$. The cell size began to increase, and the morphology becomes irregular. (C) In vitro decidualization induction for $48 \mathrm{~h}$. The cell size became bigger, the cell showed a long fusiform shape with reduced translucency. (D) In vitro decidualization induction for $72 \mathrm{~h}$, the cell volume continued to increase and the cell boundaries were blurred.

Additional file 3. Illumina RNA-Seq data of all significantly differentially expressed genes in different categories (Sheet 1, shLuman vs shNC at $0 \mathrm{~h}$ decidualization; Sheet 2, shLuman vs shNC at $48 \mathrm{~h}$ decidualization; Sheet 3, shLuman vs shNC at $72 \mathrm{~h}$ decidualization).

Additional file 4. List of differentially expressed genes enriched in different signal pathways. (Sheet 1, shLuman vs shNC at $48 \mathrm{~h}$ decidualization; Sheet 2, shLuman vs shNC at $72 \mathrm{~h}$ decidualization).

Additional file $\mathbf{5}$. Sequences of primer pairs for RT- $\mathrm{qPCR}$.

\section{Abbreviations}

BFA: Brefeldin A; CREB: CAMP responsive element-binding; DEGs: Differentially expressed genes; E2: estrogen; ERAD: ER-associated protein degradation; ESC: Endometrial stromal cell; FPKM: Fragments Per Kilobase of transcript sequence per Millions base pairs sequenced; KEGG: Kyoto Encyclopedia of Genes and Genomes; P4: progesterone; UPR: Unfolded protein response

\section{Acknowledgements}

Not applicable.

\section{Authors' contributions}

FZ, YY, YJ: Conceived and designed this study. FZ, HL, NW, LY: endometrial stromal cell isolation, lentivirus packaging and transfection, RNA isolation and gene expression analysis. FZ, AW, YY: data analysis and manuscript writing. All authors read and approved the final manuscript.

\section{Funding}

This research was supported by the Key Technology R\&D Program of Ningxia Hui Autonomous Region (No. 2018BBF33001) and by the National Natural Science Foundation of China (No. 31772817). The funding bodies had not role in the design of the study and collection, analysis, and interpretation of data or in writing the manuscript.

\section{Availability of data and materials}

The datasets supporting the conclusions of this article are included within the article and Additional files 1, 2, 3, 4, 5. Complete RNA-seq datasets are available from NCBI (accession NO. SRP216935).

\section{Ethics approval}

All procedures involving animals conformed to Guidelines on Humane Treatment of Laboratory Animals by the Ministry of Science and Technology of China and were approved by the Committee for the Ethics on Animal Care and Experiments in Northwest A\&F University.

\section{Consent for publication}

Not applicable.

\section{Competing interests}

The authors declare that they have no competing interests.

\section{Author details}

${ }^{1}$ College of Veterinary Medicine, Northwest A\&F University, Yangling 712100, Shaanxi, China. ${ }^{2}$ College of Animal Science and Technology, Northwest A\&F University, Yangling 712100, Shaanxi, China. ${ }^{3}$ Institute of Biological Resources and Diversity, College of Life Sciences, China Jiliang University, Hangzhou 310018, Zhejiang, China. ${ }^{4}$ College of Food Science and Engineering, Northwest A\&F University, Yangling 712100, Shaanxi, China. 
Received: 14 August 2019 Accepted: 20 January 2020

Published online: 30 January 2020

\section{References}

1. Yoshie M, Tamura K, Hara T, Kogo H. Expression of stathmin family genes in the murine uterus during early pregnancy. Mol Reprod Dev. 2006;73(2):164-72.

2. Brighton PJ, Maruyama Y, Fishwick K, Vrljicak P, Tewary S, Fujihara R, et al. Clearance of senescent decidual cells by uterine natural killer cells in cycling human endometrium. Elife. 2017;6:e31274.

3. Dey SK, Lim H, Das SK, Reese J, Paria BC, Daikoku T, et al. Molecular cues to implantation. Endocr Rev. 2004;25(3):341-73.

4. Shindoh H, Okada H, Tsuzuki T, Nishigaki A, Kanzaki H. Requirement of heart and neural crest derivatives-expressed transcript 2 during decidualization of human endometrial stromal cells in vitro. Fertil Steril. 2014;101(6):1781-90.

5. Tsai MJ, O'Malley BW. Molecular mechanisms of action of steroid/thyroid receptor superfamily members. Annu Rev Biochem. 1994;63(1):451-86.

6. Lydon JP, DeMayo FJ, Funk CR, Mani SK, Hughes AR, Montgomery CA, et al. Mice lacking progesterone receptor exhibit pleiotropic reproductive abnormalities. Genes Dev. 1995;9(18):2266-78.

7. Ramathal CY, Bagchi IC, Taylor RN, Bagchi MK. Endometrial decidualization: of mice and men. Semin Reprod Med. 2010;28(1):17-26.

8. Lim H, Ma L, Ma WG, Maas RL, Dey SK. Hoxa-10 regulates uterine stromal cell responsiveness to progesterone during implantation and decidualization in the mouse. Mol Endocrinol. 1999;13(6):1005-17.

9. Mantena SR, Kannan A, Cheon YP, Li Q, Johnson PF, Bagchi IC, et al. C/EBP $\beta$ is a critical mediator of steroid hormone-regulated cell proliferation and differentiation in the uterine epithelium and stroma. Proc Natl Acad Sci U S A. 2006:103(6):1870-5.

10. Wang W, Li Q, Bagchi IC, Bagchi MK. The CCAAT/enhancer binding protein beta is a critical regulator of steroid-induced mitotic expansion of uterine stromal cells during decidualization. Endocrinology. 2010;151(8):3929-40.

11. Adham IM, Eck TJ, Mierau K, Müller N, Sallam MA, Paprotta I, et al. Reduction of spermatogenesis but not fertility in Creb314-deficient mice. Mol Cell Biol. 2005;25(17):7657-64

12. Jin DY, Wang HL, Zhou Y, Chun AC, Kibler KV, Hou YD, et al. Hepatitis C virus core protein-induced loss of LZIP function correlates with cellular transformation. EMBO J. 2000;19(4):729-40

13. Eleveld-Trancikova D, Sanecka A, van Hout-Kuijer MA, Looman MW, Hendriks IA, Jansen BJ, et al. DC-STAMP interacts with ER-resident transcription factor LUMAN which becomes activated during DC maturation. Mol Immunol. 2010;47(11-12):1963-73.

14. Penney J, Mendell A, Zeng M, Tran K, Lymer J, Turner PV, et al. LUMAN/ CREB3 is a key regulator of glucocorticoid-mediated stress responses. Mol Cell Endocrinol. 2017;439(5):95-104.

15. Lan $X$, Jin $Y$, Yang $Y$, Lin P, Hu L, Cui C, et al. Expression and localization of Luman RNA and protein during mouse implantation and decidualization. Theriogenology. 2013;80(2):138-44.

16. Behnke J, Feige MJ, Hendershot LM. BiP and its nucleotide exchange factors Grp170 and Sil1: mechanisms of action and biological functions. J Mol Biol. 2015;427(7):1589-608.

17. Costa CZ, da Rosa SE, de Camargo MM. The unfolded protein response: how protein folding became a restrictive aspect for innate immunity and $B$ lymphocytes. Scand J Immunol. 2011;73(5):436-48.

18. Lu R, Yang P, O'Hare P, Misra V. Luman, a new member of the CREB/ATF family, binds to herpes simplex virus VP16-associated host cellular factor. Mol Cell Biol. 1997:17(9):5117-26.

19. Termine DJ, Moremen KW, Sifers RN. The mammalian UPR boosts glycoprotein ERAD by suppressing the proteolytic downregulation of ER mannosidase I. J Cell Sci. 2009;122(7):976-84.

20. Nakatsukasa K, Brodsky JL. The recognition and retrotranslocation of misfolded proteins from the endoplasmic reticulum. Traffic. 2008;9(6):861-70.

21. Lee KY, Jeong JW, Wang J, Ma L, Martin JF, Tsai SY, et al. Bmp2 is critical for the murine uterine decidual response. Mol Cell Biol. 2007;27(15):5468-78.

22. Zhou WJ, Hou XX, Wang XQ, Li DJ. Fibroblast growth factor 7 regulates proliferation and decidualization of human endometrial stromal cells via ERK and JNK pathway in an autocrine manner. Reprod Sci. 2017;24(12):1607-19.

23. Anteby EY, Natanson-Yaron S, Hamani Y, Sciaki Y, Goldman-Wohl D, Greenfield C, et al. Fibroblast growth factor-10 and fibroblast growth factor receptors 1-4: expression and peptide localization in human decidua and placenta. Eur J Obstet Gynecol Reprod Biol. 2005;119(1):27-35.
24. Mazerbourg S, Sangkuhl K, Luo CW, Sudo S, Klein C, Hsueh AJ. Identification of receptors and signaling pathways for orphan bone morphogenetic protein/growth differentiation factor ligands based on genomic analyses. J Biol Chem. 2005;280(37):32122-32.

25. Franco HL, Dai D, Lee KY, Rubel CA, Roop D, Boerboom D, et al. WNT4 is a key regulator of normal postnatal uterine development and progesterone signaling during embryo implantation and decidualization in the mouse. FASEB J. 2011;25(4):1176-87.

26. Afshar Y, Jeong JW, Roqueiro D, DeMayo F, Lydon J, Radtke F, et al. Notch1 mediates uterine stromal differentiation and is critical for complete decidualization in the mouse. FASEB J. 2012;26(1):282-94.

27. Burnett T, Tash J, Hunt J. Investigation of the role of nitric oxide synthase 2 in pregnancy using mutant mice. Reproduction. 2002;124(1):49-57.

28. Aplin JD, Jones CJ. Extracellular matrix in endometrium and decidua. In: Placenta as a Model and a Source. Boston: Springer; 1989. p. 115-28.

29. Vallejo G, Maschi D, Mestre-Citrinovitz AC, Aiba K, Maronna R, Yohai V, et al. Changes in global gene expression during in vitro decidualization of rat endometrial stromal cells. J Cell Physiol. 2010;222(1):127-37.

30. Favaro R, Abrahamsohn PA, Zorn MT. Decidualization and endometrial extracellular matrix remodeling: the guide to investigation of mouse pregnancy. Boston: Academic Press; 2014. p. 125-42.

31. Shiokawa S, Yoshimura Y, Nagamatsu S, Sawa H, Hanashi H, Sakai K, et al. Functional role of focal adhesion kinase in the process of implantation. Mol Hum Reprod. 1998;4(9):907-14.

32. Kaneko Y, Lindsay LA, Murphy CR. Focal adhesions disassemble during early pregnancy in rat uterine epithelial cells. Reprod Fertil Dev. 2008;20(8):892-9.

33. Fabi F, Grenier K, Parent S, Adam P, Tardif L, Leblanc V, et al. Regulation of the PI3K/Akt pathway during decidualization of endometrial stromal cells. PLoS One. 2017;12(5):e0177387.

34. Zhang X, Fu LJ, Liu XQ, Hu ZY, Jiang Y, Gao RF, et al. nm23 regulates decidualization through the PI3K-Akt-mTOR signaling pathways in mice and humans. Hum Reprod. 2016;31(10):2339-51.

35. He H, Kong S, Liu F, Zhang S, Jiang Y, Liao Y, et al. Rbbp7 is required for uterine stromal decidualization in mice. Biol Reprod. 2015;93(1):13.

36. Zhao F, Wang N, Yi Y, Lin P, Tang K, Wang A, et al. Knockdown of CREB3/ luman by shRNA in mouse granulosa cells results in decreased estradiol and progesterone synthesis and promotes cell proliferation. PLoS One. 2016; 11(12): 0168246

37. Chen F, Wang N, Yang D, Wen X, Mahmoud TN, Zhou D, et al. Herp depletion arrests the $S$ phase of the cell cycle and increases estradiol synthesis in mouse granulosa cells. J Reprod Dev. 2016;62(2):159-66.

38. Khan A, Fornes O, Stigliani A, Gheorghe M, Castro-Mondragon JA, van der Lee R, Bessy A, Cheneby J, Kulkarni SR. Tan GJNar: JASPAR 2018: update of the open-access database of transcription factor binding profiles and its web framework. Nucleic Acids Res. 2017;46(D1):D260-6.

\section{Publisher's Note}

Springer Nature remains neutral with regard to jurisdictional claims in published maps and institutional affiliations.

\section{Ready to submit your research? Choose BMC and benefit from:}

- fast, convenient online submission

- thorough peer review by experienced researchers in your field

- rapid publication on acceptance

- support for research data, including large and complex data types

- gold Open Access which fosters wider collaboration and increased citations

- maximum visibility for your research: over $100 \mathrm{M}$ website views per year

At BMC, research is always in progress.

Learn more biomedcentral.com/submissions 